Motherhood and Graduate Education: 1970-2000

By: Arielle Kuperberg

Kuperberg, Arielle. 2009. "Motherhood and Graduate Education, 1970-2000"Population

Research and Policy Review. 28(4): 473-504

$* * *$ Reprinted with permission. No further reproduction is authorized without written
permission from Springer Verlag. This version of the document is not the version of record.
Figures and/or pictures may be missing from this format of the document. $* * *$

The final publication is available at http://ink.springer.com/article/10.1007/s11113-008-9108$\underline{3}$

\begin{abstract}
:
This study examines issues related to the fertility of graduate students over time. First, it examines changes in motherhood rates between 1970 and 2000 among women aged 20-49 who are enrolled in graduate school, both by themselves and relative to prevailing trends among women not enrolled in graduate school, and to other college educated women. Overall, women enrolled in graduate school are increasingly likely to be mothers of young children, and are increasingly similar to non-graduate students. Second, it examines the timing of these births, and finds that almost half of births occur while women are enrolled in graduate school. Third, a brief review of current maternity leave policies and childcare options available to graduate students is presented. Results are discussed in terms of institutional changes within academia, changes between cohorts that attended graduate school in these decades, and the policy needs of graduate student mothers.
\end{abstract}

Keywords: Motherhood | Fertility | Graduate school | Graduate students | Higher education

\title{
Article:
}

The 1970s were a decade of extensive social change with respect to gender roles in the United States. Women entered the labor force at sharply increased rates, married less frequently, and married and had children later in life (Goldin 2004). Coinciding with and as a result of their entry into the labor market, between 1970 and 2000 there was a sharp increase in the number of women obtaining education beyond the baccalaureate degree, both in absolute terms and relative to men (see Table 1). Women have risen from 10.5\% of doctoral recipients in 1970 to $45 \%$ in 2000, from 6\% of professional school graduates (programs in medicine, law, dentistry, pharmacy, veterinary medicine, and theology) in 1970 to $46 \%$ of graduates in 2000, and from $40 \%$ of masters students in 1970 to $58.5 \%$ in 2000 (U.S. Department of Education 2003). As women have spent an extended period of time on their education, it has become more common for women to marry and have children while they are still enrolled in school (Cooksey and Rindfuss 2001; Sandefur et al.2005, p. 292).

Table 1 
Percent of graduate degrees awarded to women

\begin{tabular}{|c|c|c|c|}
\hline & MA & Phd/EdD & First professional degree \\
\hline 1960 & 31.70 & 10.50 & 2.70 \\
\hline 1970 & 40.10 & 14.30 & 6.30 \\
\hline 1976 & 47.13 & 24.42 & 18.72 \\
\hline 1980 & 50.48 & 31.19 & 26.84 \\
\hline 1988 & 51.94 & 36.63 & 36.43 \\
\hline 1992 & 54.20 & 38.12 & 40.11 \\
\hline 1996 & 56.86 & 40.83 & 42.13 \\
\hline 2000 & 58.53 & 44.93 & 46.23 \\
\hline
\end{tabular}

Source: U.S. Department of Education, National Center for Education Statistics

Women who have children while enrolled in school may experience more role strain while trying to balance education and family, fueling higher drop-out rates for these women (Rindfuss et al. 1980). In high status jobs requiring a graduate education, having children and the subsequent role strain associated with childcare may disadvantage women in terms of completing their education, leading to a smaller proportion of women at high ranks in these occupations. This represents an early stage in a situation characterized as a 'leaky pipeline', whereas women (and especially mothers) are more likely than men to drop out of the 'pipeline' of established career trajectories (Dugger 2001; Rothblum 1988; Valian 2004). A major culprit in these 'leaks' is motherhood; Mason and Goulden (2002) find that when compared with men with PhDs who have early children, women with PhDs who have at least one child early in their careers (defined as earlier than 5 years after obtaining their PhD) are 24\% less likely in the sciences and 20\% less likely in the humanities and social sciences to ever achieve tenure. However, recent research suggests that graduate school might be a better time for women to have children than in the early stages of an academic career, at least in terms of later probability of obtaining tenure (SpalterRoth and Kennelly 2004).

Although the above studies have examined the consequences of having children in graduate school or early careers, some basic information - that is, the fertility levels of students enrolled in graduate school—have not been systematically studied. Additionally, these studies have little to say on the timing of births, nor on the policy options available to graduate students which may alleviate some role strain associated with having children while still enrolled in school. It is 
important to study the fertility patterns and timing of fertility among women in graduate school to determine the extent to which policies addressing their concerns are needed, in order to create policies that specifically address their needs and ultimately reduce the amount of women 'leaking' out of occupations requiring a graduate education. This study will add to the literature by examining the question of what fertility rates of graduate students look like, and how they have changed over time. Specifically, I will examine trends in the motherhood patterns of graduate students in the United States during the years 1970-2000. Additionally, I will examine the question of when graduate student mothers are having their children (before, during, or while on a break from graduate school) in order to determine which policies may be most useful to graduate student mothers. Finally, I will briefly examine the maternity leave and childcare options available to graduate students at the top 20 research universities in the United States, in order to determine the extent to which these policies and options are available, and where improvements may be made.

\section{Motherhood and Education}

Fertility is affected by both biological and social factors. The period in which women are biologically able to have children begins at menarche, peaks in the twenties, and then declines to menopause (Weeks 2002, p. 168). Social factors play an important role in determining the number of children a woman has, and when she has them. Gauthier and Hatzius (1997) posit that fertility rates among women are determined by two factors; the desired fertility of the particular woman, and the costs involved in having a child. These costs include the direct costs of raising a child, the money lost if the new mother takes unpaid leave, and the opportunity costs of taking leave, which includes any demotions or pay cuts, as well as failure to receive promotions or raises because of time spent on leave.

Educational attainment and motherhood are entwined phenomena that are difficult to untangle. Over the past several decades, the age at first birth has become higher for all women, but this delay is more pronounced among college and postgraduate educated women (Rindfuss et al. 1996). Rindfuss et al. (1980) found that each year of education results in the delay of first birth by approximately three quarters of a year. However, there is no clear direction of causality between education and delayed childbearing. High occupational and educational aspirations may cause women to postpone motherhood, or the desire to postpone motherhood may cause women to spend more time in formal education (Rindfuss et al. 1980). However, evidence indicates that education has a much stronger effect on age at first birth than age at first birth has on education (Rindfuss et al. 1980). Regardless of the direction of causality, education is clearly related to childbearing patterns, and in more recent years the association between the two has grown stronger (Rindfuss et al. 1996).

Earlier studies show that women who obtain a graduate education have different family formation patterns than those who do not. One study of the 1970 census finds that graduate educated women are less likely to have children and less likely to get married early than college educated women, and are more prone to marital disruption (Houseknecht and Spanier 1980). Studies of motherhood outcomes for women with graduate degrees show that postponing childbearing until after completing education may lead to lower overall fertility. For instance, 
among women with PhDs who take a university job without already having children, less than one-third will become mothers within 12 years of entering the academic work force; after this point it is often too late to begin due to biological reasons (Mason and Goulden 2004a). Women in the academy are much less likely to be married than their male counterparts; female faculty tend to have children later than male faculty and have a higher rate of voluntary childlessness (Jacobs and Winslow 2004; Mason and Goulden 2004a; Rothblum 1988).

Some of these differences are due to a difference in preferences; Killien's (1987) study of professional women (79\% of whom had a graduate degree) reports that these women desired to remain childless at a rate of 2-4 times that of the general population. Miree and Frieze (1999), however, find that $81 \%$ of women with MBAs desired at least one child, but by age 40 only $66 \%$ had become mothers. Similarly, Mason and Goulden (2004b) find that fully 38\% of women on the academic tenure track had fewer children than they desired, compared with $18 \%$ of men. Why is this?

The concurrence of women's peak fertility years and the time in which they are seeking advancement in their job (such as tenure or partnership) explains this phenomenon. Having a child during the early stages of a woman's career is highly problematic for a woman who wishes to advance in her career. Past research has found that women are well aware of these consequences and that their awareness appears to directly affect their intentions to enter academia (Smulyan 2004; van Anders 2004). Working women often postpone childbearing as a way of navigating the tension between work and family. In a survey of childless female academic professionals, Kemkes-Grottenthaler (2003) finds that only $24.4 \%$ stated they did not wish to have children, or would forgo having children for their career, while $38.5 \%$ stated "Children do not agree with my current life situation" and 33.1\% stated "resources prevent it" as their reason for being childless. The strategy of pushing off childbearing until ascending the occupational hierarchy is appealing to women who wish to succeed in their fields, but this depends on successfully ascending the occupational hierarchy while they are still biologically able to have children. This strategy is not always feasible for women; women who intend to delay motherhood until their careers are established may postpone childbearing too long due to misconceptions about fertility, ending up involuntarily childless (Kemkes-Grottenthaler 2003). As a columnist in the Chronicle of Higher Education put it when discussing women in academia, "Many, many women 'forget to have children' in a frenzy to get tenure. They don't forget, of course; many regret their loss.” (Williams2004b).

Having children during school can be an appealing strategy for highly educated women who wish to have children. Graduate school has a more flexible time schedule than the formal labor market. Additionally, as graduate education is undertaken later in the lifecycle than undergraduate education, women are more likely than undergraduates to be married and/or at a point in their lives where childbearing is desirable.

It is not surprising then that motherhood is a concern of female graduate students. While the academic literature on this topic remains sparse, a review of recent advice columns in The Chronicle of Higher Education demonstrates that women enrolled in graduate school are indeed thinking about when and whether to have children (see Fleer 2004; Garms 2006; Schweber 2005; Williams 2004a, b). Unfortunately for women who wish to combine education and childbearing, 
the overwhelming message behind these articles is that academic institutions discourage having young children during graduate school; the common wisdom is that doing so will have detrimental effects on one's career. As one woman who discovered she was pregnant while in graduate school put it: “As soon as they found out I was pregnant, I feared [my committee] would cease to see me as a serious, committed scholar” (Garms 2006). Despite this negative message regarding childbearing, women in graduate school are expected to have an increasing number of children over the period studied, for a number of reasons that will be discussed below.

\section{Motherhood and Institutional Change}

Academia is an institution like any other and is influenced by the composition of its members. Before the entry of women into graduate school in great numbers, academia was primarily composed of men, to whom childbearing is not a pressing concern (as they are not personally becoming pregnant and are not primary caregivers after the birth of their children). Women's increasing presence in graduate school over the past 40 years changed the gender power balance in the academy, which may have important consequences for motherhood. Rosabeth Moss Kanter's 1977 book, Men and Women of the Corporation, examines what occurs when women increase their presence in a corporation. She finds that as the proportion of people in a minority group increase-that is, when that group moves from "token" status to "minority" status - the members can form coalitions to increase power and change the overall culture of the corporation (Kanter1977, pp. 208-209). Insofar as motherhood may be affected by institutional norms, women's increasing power within the institution of graduate school has important implications for patterns of motherhood over time.

As women's representation in the institution of graduate education increases, they should have an increased ability to favorably change the educational culture that discourages childbearing while enrolled in the educational system (assuming the institution of graduate education is similar to corporations). They can do this through advocacy for policy change and through pressure on advisors and administrators that must increasingly deal with women having children while in school. Institutions have an inherent financial interest in retaining students, as students who pay tuition (such as law and medical students) contribute directly to the budget of the school, and students who are paid by the institution (such as funded $\mathrm{PhD}$ students) represent a loss in investment if the student drops out before the program is completed. Retention rates of students also affect the reputation of the academic institution. The threat of losing an increasing absolute number of students for a period of time, or permanently, should be an impetus for change in institutional policies. As these policies change, women in turn should find it easier to have children while in graduate school. Therefore, I expect motherhood and recent motherhood rates to increase among women from 1970 to 2000. The above described phenomenon is termed the "Institutional Effect" for the remainder of this study.

There has been some evidence that graduate schools are becoming more female-friendly as women's presence in these institutions has increased. However, research concerning longitudinal changes in policies affecting female graduate students is sparse. Boulis and Jacobs (2007) find that for medical students, residency programs with a higher proportion of women residents are more likely to have family-friendly policies, such as on-site childcare and the availability of part 
time work. They also find a recent increase in maternity leave policies within medical schools. Other research finds that many $\mathrm{PhD}$ programs have begun to organize collaborative writing groups in order to reduce the isolation of female students enrolled in programs in which there are few other women (Conrad and Phillips 1995), demonstrating the growing concern for problems faced by the increasing number of female students. Mason et al. (2007) have found that only $26 \%$ of graduate schools offer maternity leave to students, but that by 2006 , fully $76 \%$ had oncampus university sponsored childcare. The issue of current maternity leave options available to students will be further examined in this paper.

Although beyond the scope of this paper, two caveats must be noted in discussing fertility and institutional change among graduate students. First, graduate students examined in this paper are not a homogenous group. Considerable variation exists in both gender composition and familyfriendly policies between different types of graduate programs within universities (for instance a master's program versus a medical school), between different fields of study within a graduate program (for instance a $\mathrm{PhD}$ in physics versus a $\mathrm{PhD}$ in English literature) and between the same type of programs or fields of study at different universities. The dispersion of women into what were once considered non-traditional fields may leave some women as a minority in their program despite the overall increase in women's representation in graduate school. Additionally, various types of graduate programs have very different structures that may contribute to the ease, or difficulty, of having children while enrolled in school. For instance, master's programs tend to include a structured set of coursework, while $\mathrm{PhD}$ programs include 2-3 years of structured coursework followed by several years of unstructured time for research. On the other hand, medical schools include some years of coursework followed by some years of medical rotations that require time commitments upwards of $50 \mathrm{~h}$ per week, and may include travel-time to distant hospitals or medical facilities.

The second important caveat to note is that institutional changes beyond gender composition may also affect the fertility of graduate students. The composition of graduate students have changed over time to include more American minority students, as well as more international students, who may have different fertility patterns regardless of graduate student status. Other institutional changes may also have occurred. This paper cannot directly test the extent to which gender composition explains fertility rates, and can only speculate as to why rates may or may not have changed in the time period studied. Future research may be able to directly address this question by examining the gender composition and fertility rates of graduate students in specific programs, and to what extent these two factors are correlated.

\section{Motherhood and Cohort Change}

It is important for studies of women's behavior to focus on changes over time. Changes in the representation of women in graduate education (discussed above), differences between cohorts, and the changing political and cultural situation of women in those cohorts all affect their behavior, particularly relating to childbearing. Earlier cohorts may represent 'pioneers' in the field, who are determined to show they could 'make it' and are trying to minimize behavior that

might draw attention to their gender; including pregnancy and childbirth. Later cohorts would 
not have this same agenda, and as Jacobs (1996) discusses, did not intend to sacrifice as much for the sake of their career as the women who preceded them.

Goldin and Katz’s study, “The Power of the Pill: Oral Contraceptives and Women's Career and Marriage Decisions," describes some important factors in cohort fertility change (Goldin and Katz 2002). This study notes the importance of birth control pills, which were first approved by the FDA in 1960, though were not widely used among single women until the late 1960s and early 1970s (Goldin and Katz 2002). Goldin and Katz argue that with the widespread availability of the birth control pill, women are able to control their fertility, delay marriage, and invest in their own human capital (including higher levels of education). In 1973, abortion was legalized in the Supreme Court's decision on Roe v. Wade, further increasing a woman's ability to plan a family. As a result of these and other factors, including women's increased labor force participation in the 1970s, women's overall fertility within the United States showed a marked decrease in the 1970s. Although fertility levels have increased after the late 1980s, fertility has not increased to pre-1970 levels (Morgan 1996). These important changes in contraceptives, abortion availability and behavior lead to the prediction of an expected drop in fertility in the years following 1970, as women in 1970 are less able to control their fertility outcomes.

Changes in birth control availability are not limited to graduate students; all women in the United States are affected by these changes. Comparing graduate students to non-graduate students should act as a control for these cohort changes in birth control availability. If graduate students' fertility increases relative to all women, it would be a result of institutional effects or other cohort effects (discussed below). The change in birth control availability to all women motivates a comparison of graduate students' fertility rates to the fertility rates of all women who are not graduate students. The result of this comparison will provide a measure of fertility that removes the effect of increased birth control availability and, to some extent, minimizes the influence of other unmeasured factors that affect the overall fertility of women in a specific country. This effect is termed the "Birth Control Cohort Effect" for the remainder of this study.

Goldin’s 2004 study, “The Long Road to the Fast Track: Career and Family,” examines values regarding work and family for cohorts that attended college at various times over the past 100 years. She finds that women who attended college in the late 1960s and early 1970s put off family in order to further their career, while women who attended college in the 1980s expected a balance of career and family. The first group of women would be enrolled in graduate education in 1970 and 1980, while the second group would be enrolled in graduate education in 1990 and 2000. This research also supports the expectation that women enrolled in graduate school will have increasingly higher rates of motherhood in more recent cohorts. Goldin's argument motivates a comparison of graduate students to other college graduates who are not enrolled in graduate school; these cohort changes in combining work and family (according to Goldin) affected all college graduates. By comparing those enrolled in graduate school to other college graduates not enrolled in graduate school, this cohort effect should be controlled for; any differences in fertility seen when comparing graduate students to other college graduates should be a result of institutional effects and not this cohort effect. This effect is termed the "WorkFamily Cohort Effect” for the remainder of this study. 
Finally, as women have an increasing presence in graduate school, and they are a less selective group, the distinctiveness of women who are enrolled in graduate education should decrease. While early cohorts studied are highly self-selected into graduate school, women who entered graduate school more recently are probably not as unique. As a result, I expect that over time women in graduate school will become more like women in the general population who are not in graduate school. This effect, termed the "selection effect," also predicts that women in graduate school will become more like non-graduate students over time.

\section{Hypotheses}

This study will look at the rates of motherhood among grad students from 1970 to 2000, in order to examine the effect of both institutional and cohort effects discussed above. The expected results and the test of each can be summarized as follows:

(1) Women enrolled in graduate school will demonstrate an increased rate of motherhood relative to earlier years (Institutional Effect).

Test: Age-standardized motherhood rates of graduate students across the four years studied.

(2) Graduate Students will become more similar to non-graduate students over time (Institutional Effect, Selection Effect) despite overall changes in fertility due to differences in birth control availability (Birth Control Cohort effect).

Test: Motherhood rate ratios of graduate students to non-graduate students

(3) All College graduates may have different fertility patterns than other women (WorkFamily Cohort Effect), but Graduate Students will increase their fertility relative to other college graduates over time (Institutional Effect, Selection Effect).

Test: Motherhood rate ratios of Graduate Students to other College Graduates

One important factor that has thus far been ignored is marital status. Although marriage is not a prerequisite to childbearing, it is an important factor for many women in determining their childbearing behavior (Morgan1996). Ignoring marital status in this study would be ignoring a major factor that may explain some differences between graduate students and other groups. Although women with higher levels of education ultimately have higher rates of marriage than those with less education (Rindfuss et al. 1996), enrollment in school decreases the rate of marriage formation (Thornton et al. 1995), as women delay marriage to complete their education. This means that women who are enrolled in graduate school will likely have lower rates of marriage than those of similar ages who have completed their education. To control for this factor, all ratios will be calculated both for all women and then for married women only. 
Regression techniques will also be employed to control for all factors discussed, as well as race (discussed further below).

\section{Data and Variables}

Data for fertility analyses are drawn from the United States Census from the years 1970, 1980, 1990 and 2000. The 1970 data are from the Form 1 state sample of the United States Census, which is a nationally representative sample that surveys $1 \%$ of the United States. These data are obtained using the IPUMS extract system using the website www.ipums.org (Ruggles et al. 2005). These samples are collected as part of the United States Census, which is conducted every 10 years. For the years 1990 and 2000, weights provided by the census are used to correct for over-sampling of certain populations.

"Graduate Student," as used in this paper, includes all students enrolled in any degree program above the baccalaureate level, including students seeking a master's degree, $\mathrm{PhD}$ or professional degree such as medical, dental or business degrees. ${ }^{1}$ Individuals are coded as graduate students if they are currently enrolled in school and if they had received the highest level of education measured in the census; 4+ years of college. This measure might pick up individuals who take longer than 4 years to complete college, but who are not graduate students. This selection method is used in order to maintain consistency across all 4 years of data. To test the accuracy of this identification method, I conducted a sensitivity test using the 2000 data, which (unlike previous years) contains a variable where individuals could indicate whether or not they are enrolled in a graduate program (see Table 2). Women in 2000 who indicate they are enrolled in graduate school yielded a sample size that had 25,206 fewer cases than the sample generated by the criteria I used, which is $27 \%$ of the total sample for that year $(n=93,592)$. Two tailed $t$-tests are calculated to determine if significant differences existed between the overall sample used in this paper and the $73 \%$ of these students who had indicated they are enrolled in graduate school in the 2000 census. Statistically significant differences are found for the race distribution, marital distribution, and average age of the student between these two groups. However, given the large sample size in the census, almost any difference would be significant; what is important to note here is that the magnitude of difference between these two groups is less than $1.5 \%$ points in all variables except age, and approximately a third of a year difference in average age. Most importantly, the outcome variable for this study - the probability of having a child under fiveis notsignificantly different between these two groups, despite the large sample sizes. Based on this sensitivity test, I conclude that using this method of identifying graduate students is appropriate for this study, although it is important to note that results will be affected to some extent by this sampling method. In terms of the outcome variable (children under five), the probability of having young children for the sample used in this paper is higher than for the sample only including graduate students, indicating that estimates in this paper may overestimate the motherhood levels of graduate students - though the difference is not statistically significant.

\section{Table 2}

Sensitivity test comparing grad attendees and sample used in this paper for the year 2000 


\begin{tabular}{|l|l|l|l|l|}
\hline & $\begin{array}{l}\text { Sample } \\
\text { used }\end{array}$ & $\begin{array}{l}\text { Grad school } \\
\text { attendes only }\end{array}$ & Student's & $\begin{array}{l}\text { Significance level (2 } \\
\text { tailed) }\end{array}$ \\
\hline $\begin{array}{l}\text { Has a child } \\
\text { under 5 }\end{array}$ & .1302 & .1278 & 0.84 & Not significant \\
\hline White & .7280 & .7421 & 4.22 & .001 \\
\hline Black & .1089 & .1030 & 2.13 & .05 \\
\hline Other race & .1630 & .1543 & 2.88 & .01 \\
\hline Married & .4643 & .4770 & 3.58 & .001 \\
\hline Single & .4306 & .4168 & 3.92 & .001 \\
\hline Divorced & .0999 & .1013 & 0.49 & Not significant \\
\hline Widowed & .0052 & .0050 & 0.16 & Not significant \\
\hline $\begin{array}{l}\text { Has older } \\
\text { child }\end{array}$ & .2666 & .2686 & 0.60 & Not significant \\
\hline Age & 32.19 & 32.55 & 25.03 & .0001 \\
\hline$N$ & 93592 & 68386 & - & - \\
\hline & & & & \\
\hline
\end{tabular}

Due to the subject of this study, motherhood, only women age 20-49 are included in all analyses. The vast majority of births occur to women age 15-49 (Preston et al. 2001). Few individuals attend graduate school before age 20, however, which is why age 20 is used as the lower bound. Rates of motherhood are examined using the variable NCHLT5, which measures the number of a woman's own children younger than five in the household and which is recoded as a dichotomous variable for presence of any children under the age of five, with the assumption that it is the presence of any children under five and not the number of children per se that is the subject of interest. Although it is not known if women had their child while enrolled in graduate school or just prior to entering, this variable provides a measure of having recent children while enrolled in graduate education (a state that exerts significant time demands on mothers). The presence of children under the age of five will be referred to as the "motherhood rate" throughout this paper, although it is possible that students who do not have children under the age of five may be mothers of older children.

Data for fertility timing are drawn from the National Longitudinal Survey of Youth, 1979 cohort. This nationally representative survey follows 12,686 young men and women who were 14- 
22 years old when first surveyed in 1979. Data is collected on an annual basis until 1994 and biannually thereafter. I use all waves of data from 1979 to 2000 to examine the timing of births to women enrolled in graduate programs during this time period, defined as those currently enrolled in school at a grade above the 4th year of college.

\section{Method}

Descriptive statistics are calculated for age, race and marital status of women graduate students. The rates of motherhood among women in graduate school are obtained for each age and year. These rates are then age standardized by weighting the age specific rates for each year by a standard age distribution. This standard age distribution is constructed by taking the unweighted average of the age distribution for female graduate students in each age category, using the formula:

$$
\mathrm{C}_{\mathrm{x}}^{\mathrm{s}}=\frac{\mathrm{C}_{\mathrm{x}}^{1970}+\mathrm{C}_{\mathrm{x}}^{1980}+\mathrm{C}_{\mathrm{x}}^{1990}+\mathrm{C}_{\mathrm{x}}^{2000}}{4}
$$

where $\mathrm{C}$ is the percentage of total female graduate students in the age category $\mathrm{x}$ for each year, and $\mathrm{C}_{\mathrm{x}}{ }^{\mathrm{s}}$ is the standard weight for age category $\mathrm{x}$. The weighted age specific motherhood rates are then summed to find the motherhood rates for each year. This number is obtained from the following formula:

$\sum \mathrm{P}^{\mathrm{j}} \mathrm{X} * \mathrm{C}^{\mathrm{s}} \mathrm{X}$

where $\mathrm{P}$ is the motherhood rate for exact age $\mathrm{x}$ in year $\mathrm{j}$, and $\mathrm{C}$ is the standard (s) age weight for exact age $\mathrm{x}$. This method of age standardization allows the ability to compare populations with different age distributions, a factor which heavily influences childbearing rates.

The changing age distribution, however, is not the only factor affecting changing motherhood rates. As discussed in the literature review, national level trends in motherhood will likely impact the rates of motherhood among women enrolled in graduate education. Marital Status and college education are important factors as well. I calculate several ratios to examine the changes in rates of motherhood among graduate students as compared to the rates among all women, among all married women, among college students, and among married college students. First, all female graduate students are compared to all female non-graduate students. Second, married female graduate students are compared to all married women who are not graduate students. Third, all female graduate students are compared to female college graduates who are not currently enrolled in school, and fourth, female married graduate students are compared to female married college graduates not currently enrolled in school.

In each of these ratios, an age standardized comparative ratio is calculated using the graduate student age weights previously obtained (note that the same graduate student age weights are used when looking at married graduate students only in order to maintain consistency across ratios). The formula for these ratios is:

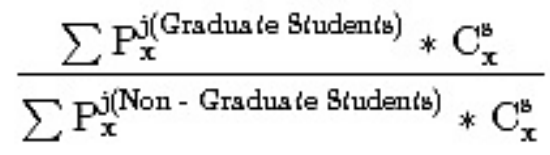


where $\mathrm{P}$ is the motherhood rate at exact age $\mathrm{x}$ for year $\mathrm{j}$ and $\mathrm{C}$ is the standard age weight for exact age $\mathrm{x}$. This ratio is then calculated for the four comparison groups discussed above. This ratio, compared across years, describes the changes in relative rates of motherhood over the time period studied, and how the motherhood rates of graduate students diverges from women who are not enrolled in school.

Finally, in order to examine how the effect of being a graduate student has changed over time, two sets of logistic regressions are calculated for the probability of having any children under five using the statistical program SAS. The first set calculates separate regressions for each year studied using all women in the US, and the second set does the same, however only women who are college graduates are examined in these regressions. All independent variables used in these formulas are dichotomous, and regressions are only calculated for women age 20-49. These models control for the presence of children older than five, education, marital status, race, and age. The reference categories for the first set of equations are women who are not graduate students and not college graduates, did not have older children, and are married, white, and age 25-29. The categories "married," "white," and "age 25-29" are chosen as references because graduate students most frequently appear in these categories in all years studied (see Table 3). The second set of regressions has the same reference categories, with only college graduates included in this regression.

\section{Table 3}

Summary statistics: women age 20-49

\begin{tabular}{|l|l|l|l|l|}
\hline & $\mathbf{1 9 7 0}$ & $\mathbf{1 9 8 0}$ & $\mathbf{1 9 9 0}$ & $\mathbf{2 0 0 0}$ \\
\hline Percent of graduate students who are female & 31.9 & 44.8 & 51.9 & 55.1 \\
\hline Number of graduate students & & & \\
\hline Female & 16,875 & 46,806 & 84,666 & 93,592 \\
\hline Male & 36,100 & 57,663 & 78,579 & 76,407 \\
\hline Average age of graduate students & & & & 32.2 \\
\hline Female & 28.8 & 30.2 & 32.3 & 31.9 \\
\hline Male & 27.7 & 29.2 & 31.4 & \\
\hline Age distribution of female graduate students & 37.5 & 24.1 & 20.0 & 23.8 \\
\hline $20-24$ & 28.7 & 31.2 & 23.9 \\
\hline $25-29$
\end{tabular}




\begin{tabular}{|c|c|c|c|c|}
\hline & 1970 & 1980 & 1990 & 2000 \\
\hline $30-34$ & 13.8 & 20.0 & 17.5 & 16.8 \\
\hline $35-39$ & 8.1 & 12.4 & 16.5 & 13.4 \\
\hline $40-44$ & 7.1 & 7.4 & 13.7 & 12.1 \\
\hline $45-49$ & 4.8 & 4.9 & 8.3 & 10.6 \\
\hline \multicolumn{5}{|l|}{ Race of female graduate students } \\
\hline White & 91.8 & 86.9 & 83.4 & 72.8 \\
\hline Black & 5.6 & 8.4 & 8.9 & 10.9 \\
\hline Other race & 2.8 & 4.7 & 7.7 & 16.3 \\
\hline \multicolumn{5}{|l|}{ Marital distribution of female graduate students } \\
\hline Married & 52.6 & 47.2 & 50.0 & 46.4 \\
\hline Separated/divorced & 5.9 & 11.0 & 10.4 & 10.0 \\
\hline Widowed & 1.1 & 0.6 & 0.6 & 0.5 \\
\hline Single & 40.4 & 41.2 & 38.9 & 43.1 \\
\hline \multicolumn{5}{|l|}{ Size of samples } \\
\hline Female graduate students & 3,375 & 46,806 & 84,666 & 93,592 \\
\hline Female married graduate students & 1,773 & 22,080 & 42,375 & 43,451 \\
\hline Female non-graduate students & 388,149 & $2,360,686$ & $2,721,979$ & $2,940,346$ \\
\hline Female, married, non-grad students & 296,544 & $1,568,858$ & $1,710,124$ & $1,755,035$ \\
\hline Female college-graduates, non-grad students & 33,607 & 322,749 & 485,555 & 643,468 \\
\hline $\begin{array}{l}\text { Female, married, college-graduates, non-grad } \\
\text { students }\end{array}$ & 25,213 & 215,696 & 362,020 & 429,626 \\
\hline All women & 391,524 & $2,407,492$ & $2,806,645$ & $3,033,938$ \\
\hline
\end{tabular}

${ }^{\mathrm{a}} 1970$ number is multiplied by five to compare the $1 \%$ sample in 1970 to the $5 \%$ samples of other years 


\section{Compositional Changes of Female Graduate Students Over Time}

Gender

Table 3 presents summary statistics for graduate students for the 4 years studied. Over the time period studied, women make up an increasing proportion of the graduate students in the sample-from 32\% in 1970 to 55\% in 2000 - and are the majority of graduate students beginning in 1990. Women increase in number at a much higher rate than men, with the population of female graduate students increasing by a factor of 5.6 during this period (from 16,875 to 93,592 students), while the population of men increases by only a factor of 2.1 , from 36,100 to 76,407 students (1970 numbers are multiplied by five to account for the different sampling rates between years). Graduate students are also increasingly represented in the population at large; Fig. 1 shows the proportion of all women who are graduate students, by age. In every year until 2000, the proportion of women in each age category increases. Between 1990 and 2000 the proportion of older women enrolled in graduate education decreases slightly, while the proportion of younger women enrolled in graduate education continues to increase. The age groups with the largest proportion of women enrolled in graduate school remains women aged 22-30, which coincides with the peak fecundity years for women (Weeks 2002, p. 168).

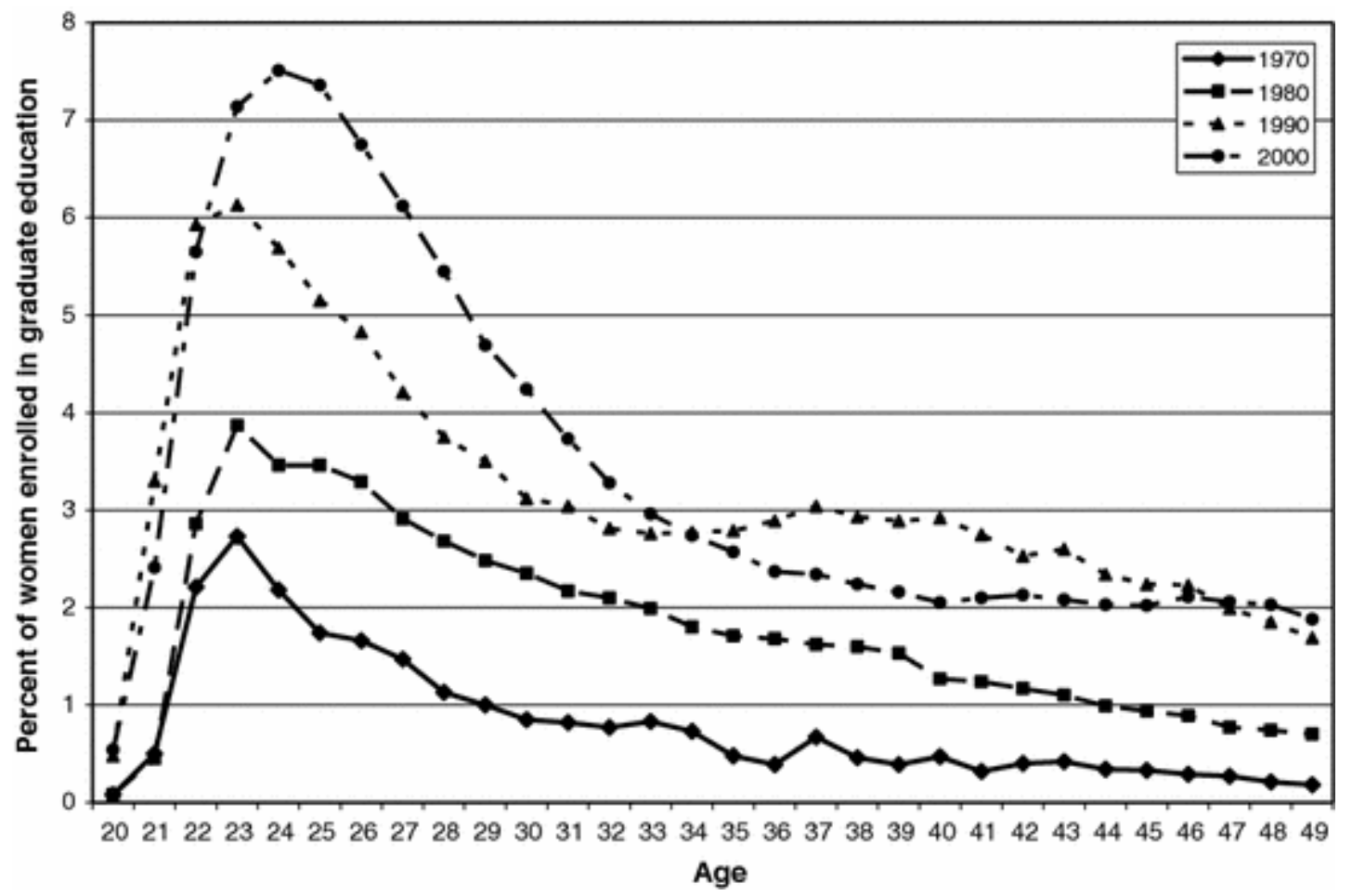

Fig. 1

Female graduate students as percentage of all women, by age, 1970-2000

Age

The age composition of female graduate students changes between 1970 and 2000, highlighting the importance of using age standardization when comparing fertility rates between these years 
(see Table 3). The average age of women enrolled in graduate education increases from 29 in 1970 to 32 in 2000. Young graduate students (age 20-24) represent a smaller proportion of graduate students; $20 \%$ in 2000 down from 37.5\% in 1970. The age category 20-24 is the largest in 1970, but in 1980 the age category 25-29 becomes the largest and remains the largest through 1990 and 2000. These results indicate that women are either increasingly taking time off between completing their undergraduate degree and enrolling in graduate education, or are in general taking a longer time to obtain their graduate degree. The concentration of graduate women in their 20s demonstrates the importance of age standardization when comparing graduate students to non-graduate students; among graduate students there are a disproportionate amount of women in the ages when women typically have children. Motherhood rates of graduate students would appear disproportionately higher in comparison with non-graduate students without age standardization.

\section{Marital Status}

Marital status of graduate students changes by a small amount over the time period studied (see Table 3). The proportion of female graduate students who are married declines from $52.6 \%$ in 1970 to $46.4 \%$ in 2000 . At the same time the proportion of female graduate students who are single (never married) increases from $40.4 \%$ in 1970 to $43 \%$ in 2000 . The proportion of students who are divorced or separated also increases in this time period from around 6\% in 1970 to $10 \%$ in 2000, which may also affect the probability of these women having children. Although the number of graduate students who are married declines over the time period studied, 'married' is the modal marital status of graduate students throughout all time periods studied. Marital status is highly correlated with fertility behavior, and several analyses in this paper will examine only married graduate students; it is important to note that they represent a decreasing proportion of female graduate students.

\section{Race}

The racial composition of graduate students changes over the time period studied as well (see Table 3). While white students still dominate the graduate classroom in 2000, they are not nearly the majority they were in 1970; their share declines from $92 \%$ of the graduate student population in 1970 to $72 \%$ in 2000. Concurrently, the representation of Black students increases steadily, from 5.6\% in 1970 to almost 12\% in 2000 (more than doubling over this time period). The representation of students of other races increases steadily by almost a factor of six, from $2.8 \%$ in 1970 to $16.6 \%$ in 2000. While racial changes are not examined in depth in this study, it is of note; as the graduate student body includes an increasing representation of minorities who have earlier motherhood timing patterns than whites (Rindfuss et al. 1996), overall motherhood rates might change as well. These changes in the racial composition of graduate students motivates the use of logistic regressions to examine the effect of being a graduate student on fertility, as such models can control for these compositional differences.

\section{Changes in Graduate Student's Fertility Over Time}

The first hypothesis states that women enrolled in graduate school will increase their rates of motherhood relative to earlier years, due to the institutional effect; that is, the increased presence 
of women in graduate school will lead to changes in their fertility behavior. At first glance, overall unstandardized rates of motherhood among graduate students do not yield a clear trend of motherhood across the 4 years studied (see Table 4 ). The proportion of female graduate students with children under five hovers between 11 and 13\%. There is a slight increase in the proportion with young children since 1980, but this is not a large increase in absolute terms.

\section{Table 4}

Motherhood rates and ratios: women age 20-49

\begin{tabular}{|c|c|c|c|c|}
\hline & 1970 & 1980 & 1990 & 2000 \\
\hline \multicolumn{5}{|l|}{ Female graduate students: percent with a child under five } \\
\hline Unstandardized & 12.33 & 11.40 & 12.72 & 13.02 \\
\hline Standardized by age & 13.41 & 10.35 & 12.14 & 12.49 \\
\hline Married only, age standardized & 20.79 & 18.54 & 22.53 & 23.27 \\
\hline \multicolumn{5}{|l|}{ Female non-grad students: percent with a child under five } \\
\hline Standardized to graduate student's age distribution & 38.47 & 28.88 & 27.99 & 27.43 \\
\hline Ratio: graduate students:: non-grad students & .3486 & .3584 & .4337 & .4553 \\
\hline \multicolumn{5}{|l|}{ Married women only } \\
\hline Non-students, age standardized & 45.99 & 39.35 & 41.5 & 42.73 \\
\hline $\begin{array}{l}\text { Ratio: married graduate students::married non-grad } \\
\text { students }\end{array}$ & .3822 & .4713 & .5488 & .5445 \\
\hline \multicolumn{5}{|c|}{ Female college grads, non-grad students: percent with a child under five } \\
\hline Standardized to graduate student’s age distribution & 29.87 & 20.01 & 20.17 & 21.56 \\
\hline Ratio: graduate students::college grads & .4491 & .5173 & 6019 & .5790 \\
\hline \multicolumn{5}{|l|}{ Married women only } \\
\hline College grads, married only, age standardized & 38.22 & 29.78 & 31.86 & 33.84 \\
\hline Ratio: married grad students::married college grads & .5439 & .6227 & .7072 & 6875 \\
\hline
\end{tabular}


After standardizing for age, definite trends in motherhood emerge. Age-standardized rates of recent motherhood start at the highest level of 13.5 in 1970, drop 3\% points (a 22.8\% decrease from the 1970 level) between 1970 and 1980 during the time period in which women first entered graduate education en masse, and then partially recover, increasing by $2 \%$ points (a 17.3\% increase from the 1980 level) between 1980 and 1990, before it plateaus between 1990 and 2000 (with a 3\% increase from the 1990 level). Age standardized rates of recent motherhood in 2000 do not recover to 1970 levels, but increase from the low level of $10.3 \%$ in 1980 to $12.5 \%$ in 2000 .

While motherhood rates drop among all graduate women with the mass entry of women into graduate education between 1970 and 1980, the subsequent increase in motherhood is due primarily to changes among older graduate students. The decreasing rate of motherhood between 1970 and 1980 is driven by declining motherhood among students under the age of 31 (see Fig. 2). After 1980, the motherhood rates among graduate students age 20-31 stay at approximately the same level, while the motherhood rates among graduate students age 32-49 increases in every year studied.

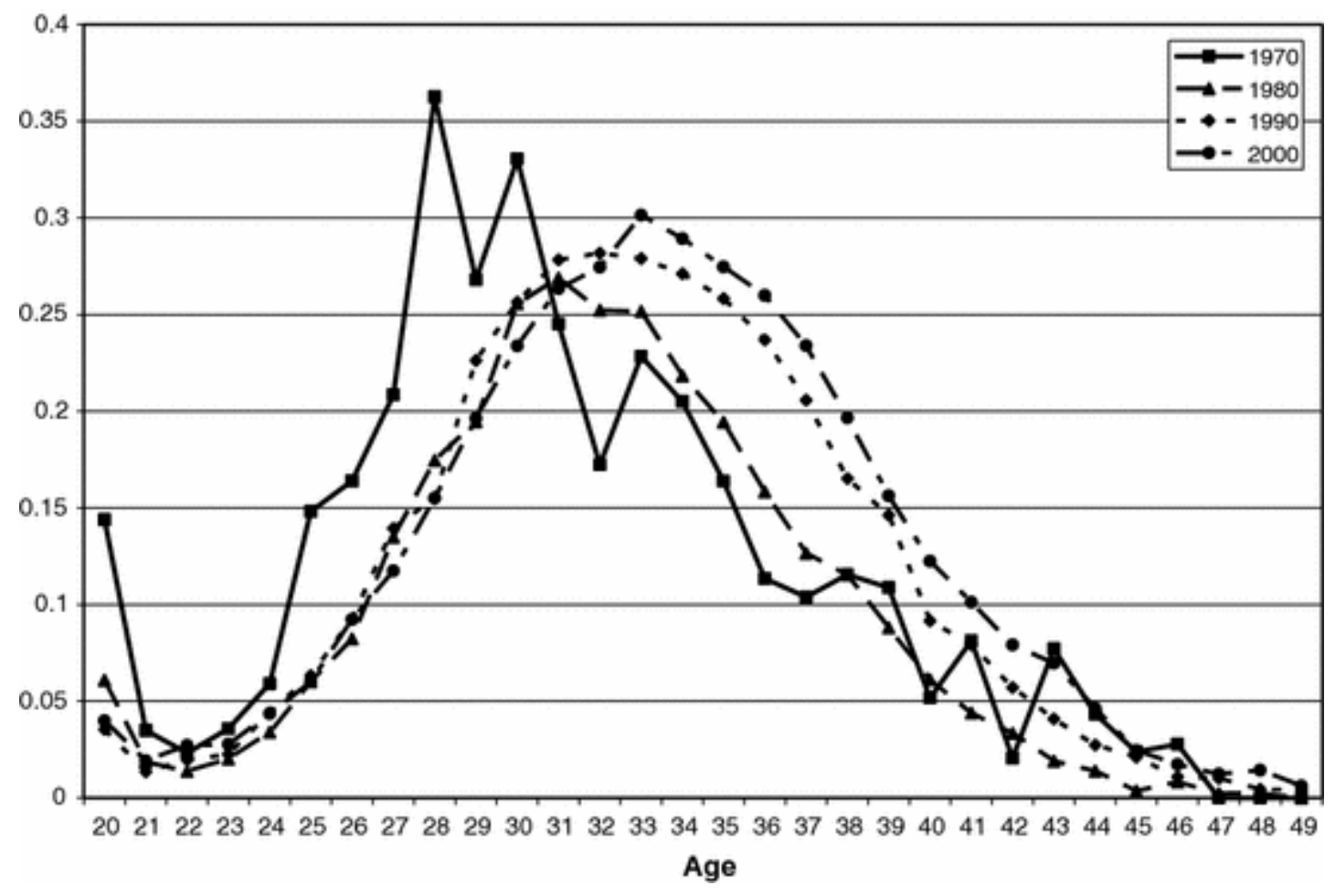

Fig. 2

Percent of female graduate students with any children under five, 1970-2000

Changes in the distribution of marital status may affect the overall fertility of the graduate student population. To control for these changes in marital status distribution, I examine age standardized motherhood rates of married graduate students only (see Table 4). Married graduate students have a higher overall level of motherhood in all years studied, but exhibit the same pattern as all graduate students over time; motherhood drops between 1970 and 1980 from a rate of 21 to $18.5 \%$, and then rises subsequent to 1980 , with a $4 \%$ point increase to $22.5 \%$ in 1990 
and a smaller increase to $23 \%$ in 2000 . Unlike the rates of motherhood among all graduate students, 2000 levels of motherhood among married graduate students exceed 1970 levels. Overall, the first hypothesis - that female graduate students will increase their fertility as they increase their presence in graduate school—is supported when using 1980 as the baseline of comparison, but is not when using 1970 as the baseline. When examining all graduate students and only married graduate students, rates first fall between 1970 and 1980 before rising between 1980 and 1990 and then increasing slightly more between 1990 and 2000. For all graduate students in 2000, motherhood levels are below 1970 motherhood levels, but when examining only married students, 2000 levels exceed 1970 levels. The most dramatic increase in motherhood rates occurs between 1980 and 1990 for both all graduate students and married graduate students. The fall in motherhood rates between 1970 and 1980 may be due to cohort changes in birth control availability discussed above, in which case ratios comparing graduate students to other women may present a different picture.

\section{Changes in Graduate Student's Fertility Relative to all Other Women}

To account for national trends in motherhood (including birth control availability) that may affect motherhood rates of female graduate students, and to examine the extent to which graduate students may change their fertility patterns despite the changes in availability of birth control and other unmeasured factors, I calculate a ratio of graduate students' childbearing to non-graduate students' childbearing for each year studied (see Table 4). Both groups are age standardized using the same age weights calculated for graduate students. As a result, these numbers do not reflect actual rates of motherhood. Instead, they reflect the rates at which non-graduate students would be mothers or recent mothers if their age distribution matched that of graduate students.

Unlike graduate students, age standardized motherhood rates among non-graduate students consistently decline during this time period with the most drastic reduction between 1970 and 1980 , from $38 \%$ in 1970 to $28 \%$ in 1980, before it plateaus at $27 \%$ in 1990 and 2000 . During all years studied, non-graduate student rates of motherhood are higher than graduate students' rates.

As a result of these trends, the ratio of motherhood rates for female graduate students to female non-graduate students increases steadily during this time period: from .35 in 1970 to .36 in 1980 to .43 in 1990 and .46 in 2000. From 1970 to 1980 , rates of motherhood fall among both graduate students and other women. However, rates of recent motherhood among graduate students fall at a slower rate, resulting in a decrease in the difference between these two populations. The biggest increase in ratios between these groups occur between 1980 and 1990; when motherhood among non-graduate students continues to decrease, while motherhood among graduate students reverses directions and begins to increase. The small increase in the ratio from 1990 to 2000 is due to the slight decrease in recent motherhood rates among non-graduate students and the slight increase in recent motherhood rates among graduate students. Thus, this is not the result of a 'baby boom' among female graduate students. Most of the movement in fertility is among non-graduate women. However, graduate student women have defied the overall trend of decreasing fertility among all women, and as a result have consistently narrowed the gap with their non-student peers in motherhood rates. Women enrolled in graduate education are one-third as likely to have a young child as their same-age peers in 1970; in 2000 they are just under half as likely to do so. 
A similar, though slightly different, pattern emerges when looking at only married graduate students and non-graduate students. Married non-graduate students demonstrate a different pattern in fertility than all non-graduate students, as their motherhood rates do not show a steady decline. Between 1970 and 1980, married non-graduate students showed a nearly 7\% decline in motherhood rates from 46 to 39\%; however since then their rates of motherhood have been slowly increasing to 41\% in 1990 and 43\% in 2000, albeit not to 1970 levels. When comparing married graduate students to married non-graduate students, the ratio increases from $45 \%$ in 1970 to $47 \%$ in 1980 . It jumps to nearly 55\% in 1990 before declining less than half a percentage point to around $54.5 \%$ in 2000. This difference between 1990 and 2000 can be interpreted as the "plateauing" of fertility differences, and it is interesting to note that the biggest decade of change here is again the 1980s. Married graduate students are more similar to married non-graduate students than overall graduate students are to overall non-graduate students, with married graduate women in 2000 more than $54 \%$ as likely to be mothers as their married non-graduate student counterparts.

To add in controls for marital status, education, having an older child, and race, I calculate logistic regressions for the odds of having at least one child under the age of five. These regressions are calculated separately for each year studied to examine the changes between years in the effect that graduate education has on the likelihood of being a mother. The first set of regressions examines all women. The odds ratios for the variables studied are presented in Table 5.

\section{Table 5}

Logistic regressions predicting the presence of children under five in the household: women age 20-49 (beta coefficients in parenthesis)

\begin{tabular}{|c|c|c|c|c|c|c|c|c|}
\hline & \multicolumn{4}{|c|}{ All women } & \multicolumn{4}{|c|}{ College graduates only } \\
\hline & 1970 & 1980 & 1990 & 2000 & 1970 & 1980 & 1990 & 2000 \\
\hline Intercept & $(0.36)$ & $(0.09)$ & $(0.23)$ & $(0.21)$ & $(0.35)$ & $(-0.26)$ & $(-0.33)$ & $(-0.35)$ \\
\hline Grad student & 0.30 & 0.41 & 0.44 & 0.40 & 0.37 & 0.49 & 0.58 & 0.57 \\
\hline $\begin{array}{l}\quad \text { College } \\
\text { graduate } \\
\text { (not enrolled } \\
\text { in school) }\end{array}$ & 1.09 & 1.01 & 0.84 & 0.79 & - & - & - & - \\
\hline $\begin{array}{l}\text { Non- } \\
\text { college } \\
\text { graduate } \\
\text { (reference) }\end{array}$ & - & - & - & - & - & - & - & - \\
\hline Older child & 1.28 & 1.16 & 1.23 & 1.36 & 1.07 & 1.06 & 0.93 & $1.00^{\mathrm{NS}}$ \\
\hline
\end{tabular}




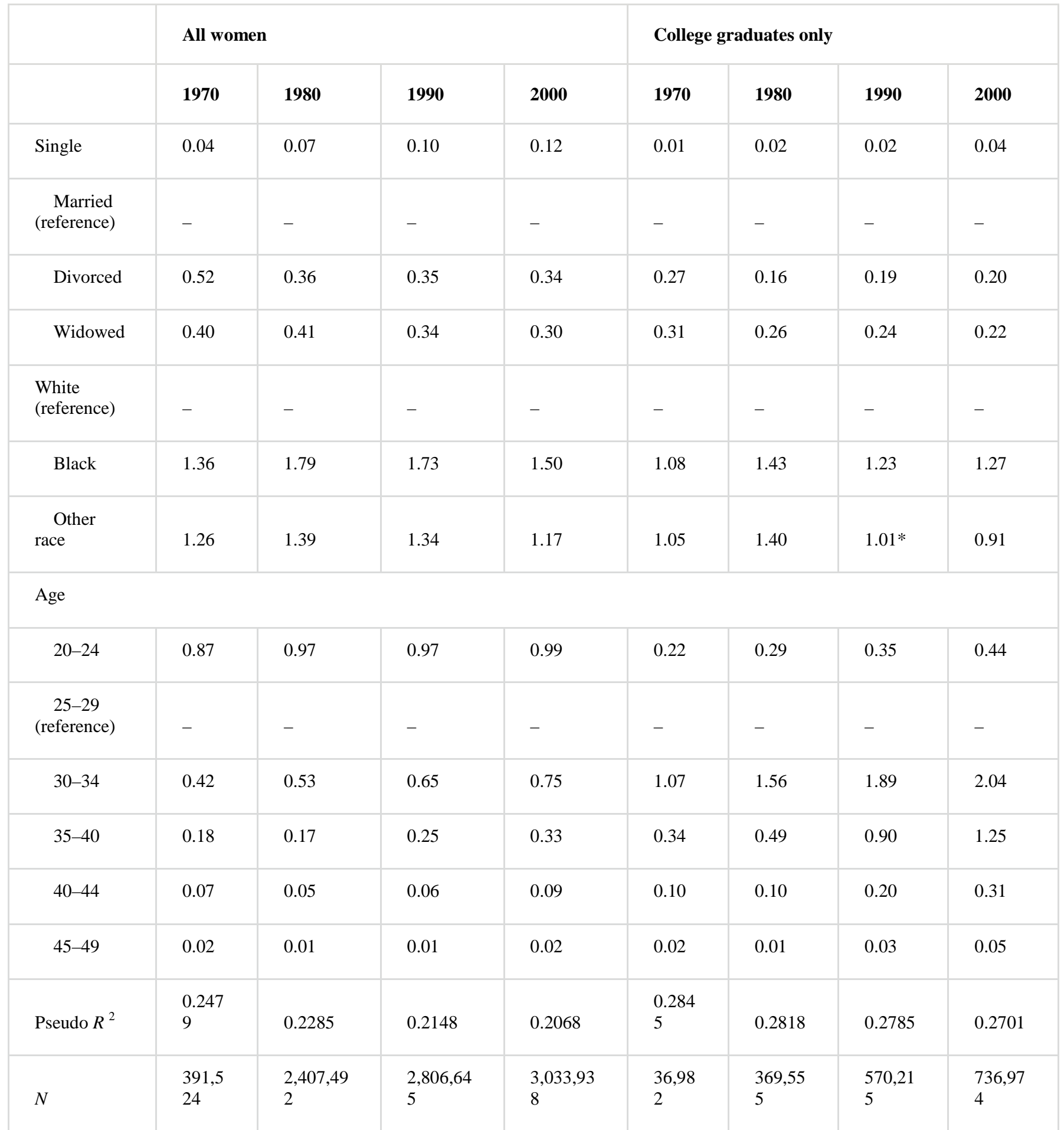

Note: All variables are significant at the $P<.0001$ level unless marked NS (insignificant) or $*(P<.01)$

As expected, being a graduate student reduces the odds of being a mother. With these added controls, having the status of a graduate student reduces the odds of being a mother by $70 \%$ in 1970, 59\% in 1980, 56\% in 1990 and 60\% in 2000. These results indicate that the effect of being enrolled in graduate school on the probability of having children under five weakened between 1970 and 1990, and then regained some strength between 1990 and 2000, although the effect did 
not return to 1970 levels. Furthermore, over this time period, the model is less able to explain motherhood rates; pseudo $R^{2}$ are calculated, and the model steadily decreases in the amount of variation in can explain over time. For 1970 , the model explains almost $25 \%$ of variation, and it explains slightly over $20 \%$ of variation for 2000 .

Overall, the second hypothesis - that graduate students will become more like non-graduate students over time-is fully supported by the ratios calculated, and partially supported by logistic regressions. Ratios for both all women and married women support the idea that graduate women are becoming more like non-graduate women in their fertility patterns. Regressions indicate that graduate women become more like non-graduate women from 1970 to 1990 . Between 1990 and 2000, however, the effect of being a graduate student strengthens, but the effect of being a graduate student in 2000 results in a $60 \%$ reduction in the probability of having a young child, which remains $10 \%$ higher than the $70 \%$ reduction in the probability of having a young child in 1970.

\section{Changes in Graduate Student's Fertility Relative to Other College Graduates}

The final hypothesis is that graduate students will increase their motherhood rates relative to other college graduates. More recent cohorts of college graduates intend to combine work and family to a larger extent than older cohorts, as discussed by Goldin (2004), and as a result should have increased fertility over time. This cohort change affects both college graduates and graduate students, so calculating ratios of graduate students to college students should eliminate (or at least greatly reduce) the impact this change in fertility intentions has on fertility rates. Comparing these two groups also controls for other cohort factors, such as birth control and abortion availability. The effect that remains should be an institutional effect; that is, any variability in the relative motherhood rates of graduate students to college graduates should be a result of both the increasing number of women in the institution of graduate school, and the decreasing selectivity of women who enter this institution.

Results show that, as with other ratios calculated in this paper, the decade between 1980 and 1990 is the period of greatest change (see Table 4). The motherhood ratio of graduate students to all other college graduates increases from $45 \%$ to nearly $52 \%$ between 1970 and 1980 . It jumps to $60 \%$ in 1990 , and declines slightly to $58 \%$ in 2000 . Among married graduate students and married college graduates only, the ratio increases from $54 \%$ in 1970 to $62 \%$ in 1980 , and jumps to nearly 71\% in 1990 before declining slightly, to around 69\% in 2000.

Not surprisingly, graduate students in all years are more like college graduates than all women. Among married women only, graduate students end at an astonishingly high rate of motherhood as compared to married college students not enrolled in school; nearly $70 \%$ of the motherhood rate of college students in 2000, representing almost double the 1970 ratio of $45 \%$. The increase over time suggests not only an institutional effect, in that women are increasing their fertility rates relative to earlier years, but also a selection effect. Women enrolled in graduate school are becoming more like non-graduate students, and are increasingly less likely to reduce their fertility behavior as a response to being enrolled in graduate school. 
Regression results are similar to ratios and show a decreasing effect of being a graduate student on motherhood rates over time. In 1970, women enrolled in graduate school are only $37 \%$ as likely as college graduates not enrolled in graduate school to have a child under the age of five, net of the presence of older children, marital status, race, and age. In 1980, graduate students are about half as likely as other college graduates to have children under five. By 1990, they are 58\% as likely, and are $57 \%$ as likely in 2000 . Unlike the regressions examining all women, the pseudo $R^{2}$ remains high for these regressions, at around $28.5 \%$ in 1970 and only declining to $27 \%$ in 2000, suggesting that this model is a better fit when studying college graduates only, and that other factors that affect fertility play a role in predicting the behavior of non-college graduates.

The hypothesis that graduate students will become more like non-enrolled college graduates over time is supported by these findings, with the caveat that ratios show a small decline between 1990 and 2000. However, ratios of 2000 motherhood rates are still well above those of 1970 rates, and the effect of being a graduate student on motherhood rates is weaker in 2000 than in 1970.

\section{Timing of Fertility}

Although the census can provide information on the number of women with children under the age of five in a given year, it cannot provide information on the exact timing of births. Are women having children while enrolled in school, before enrolling in school, or do they take time off from graduate school to have children? The answer to these questions can provide important clues for the policy needs of graduate students. To examine the timing of fertility, I examine the 1979 cohort of the National Longitudinal Survey of Youth.

To approximate the method used to examine fertility rates with the census, I examine four focal years and the women who are enrolled in graduate school and have children under the age of five in those focal years. I then examine the timing of their births and the relationship of that timing to their graduate school attendance by examining all past and future graduate school enrollments available in the dataset. The 4 years chosen for review were 1985, at which time survey participants were age 20-28, 1990, at which time students were age 25-33, 1996 (survey data was not collected in 1995) when students were age 31-39 and 2000 when students were age 3543. This includes 2 years examined above with the census (1990 and 2000) and two interim years, so that more complete data on fertility could be examined. Results are presented in Table 6.

\section{Table 6}

Timing of births, women age 20-43 (data from the National Longitudinal Survey of Youth, 1979 cohort)

\begin{tabular}{|l|l|l|l|l|l|l|}
\hline $\begin{array}{l}\text { Year attending } \\
\text { grad school: }\end{array}$ & 1985 & 1990 & 1996 & 2000 & Total & $\begin{array}{l}\text { Proportion } \\
\text { total births }\end{array}$ \\
\hline
\end{tabular}




\begin{tabular}{|c|c|c|c|c|c|c|}
\hline Births occurring & $\begin{array}{l}1981- \\
1985\end{array}$ & $\begin{array}{l}1986- \\
1990\end{array}$ & $\begin{array}{l}1992- \\
1996\end{array}$ & $\begin{array}{l}1996- \\
2000\end{array}$ & & \\
\hline $\begin{array}{l}\text { Attending } \\
\text { graduate school at } \\
\text { time of birth }\end{array}$ & 4 & 6 & 9 & 1 & 20 & 0.46 \\
\hline $\begin{array}{l}\text { Left or finished } \\
\text { by next year/next } \\
\text { interview }\end{array}$ & & & & & 9 & \\
\hline $\begin{array}{l}\quad \text { Returned } \\
\text { Later-before baby } \\
5\end{array}$ & & & & & 2 & \\
\hline $\begin{array}{c}\text { Returned } \\
\text { Later-after baby } 5\end{array}$ & & & & & 1 & \\
\hline $\begin{array}{l}\text { Started graduate } \\
\text { school after birth }\end{array}$ & 2 & 4 & 3 & 1 & 10 & 0.23 \\
\hline
\end{tabular}

Age of child when started grad school

\begin{tabular}{|c|c|c|c|c|c|c|}
\hline 1 & & & & & 1 & \\
\hline 2 & & & & & 3 & \\
\hline 3 & & & & & 3 & \\
\hline 4 & & & & & 2 & \\
\hline $\begin{array}{l}\text { Took time off } \\
\text { from graduate } \\
\text { school }\end{array}$ & 0 & 7 & 5 & 2 & 14 & 0.32 \\
\hline $\begin{array}{l}\text { Left year of } \\
\text { birth }\end{array}$ & & & & & 1 & \\
\hline $\begin{array}{l}\text { Left more than } \\
\text { one year before } \\
\text { birth }\end{array}$ & & & & & 11 & \\
\hline \multicolumn{7}{|c|}{ Age of child when returned to grad school } \\
\hline 1 & & & & & 6 & \\
\hline
\end{tabular}




\begin{tabular}{|c|c|c|c|c|c|c|}
\hline Year attending & 1985 & 1990 & 1996 & 2000 & & \\
\hline Births occurring & $\begin{array}{l}1981- \\
1985\end{array}$ & $\begin{array}{l}1986- \\
1990\end{array}$ & $\begin{array}{l}1992- \\
1996\end{array}$ & $\begin{array}{l}1996- \\
2000\end{array}$ & & total Dirtns \\
\hline 2 & & & & & 5 & \\
\hline 3 & & & & & 0 & \\
\hline 4 & & & & & 1 & \\
\hline $\begin{array}{l}\text { Birth during non- } \\
\text { interview year }\end{array}$ & 0 & 0 & 6 & 1 & 7 & \\
\hline \multicolumn{7}{|c|}{ Total attended school while children age } \\
\hline 0 & & & & & 20 & 0.45 \\
\hline 1 & & & & & 19 & 0.43 \\
\hline 2 & & & & & 19 & 0.43 \\
\hline 3 & & & & & 12 & 0.27 \\
\hline 4 & & & & & 12 & 0.27 \\
\hline Total births & 6 & 17 & 23 & 5 & 51 & \\
\hline $\begin{array}{l}\text { Total births } \\
\text { (excluding those } \\
\text { born in non- } \\
\text { interview years) }\end{array}$ & 6 & 17 & 17 & 4 & 44 & \\
\hline Total mothers & 6 & 16 & 17 & 5 & 44 & \\
\hline $\begin{array}{l}\text { Total female } \\
\text { graduate students }\end{array}$ & 123 & 80 & 59 & 45 & 307 & \\
\hline $\begin{array}{l}\text { Percent of female } \\
\text { graduate students } \\
\text { who are mothers }\end{array}$ & $4.80 \%$ & $17.50 \%$ & $28.81 \%$ & $11.11 \%$ & $14.33 \%$ & \\
\hline Age of sample & $20-28$ & $25-33$ & $31-39$ & $35-43$ & $20-43$ & \\
\hline
\end{tabular}


${ }^{\mathrm{a}}$ Excludes non-interview year births

For the four focal years chosen, a total of 44 graduate student mothers out of 307 female graduate students were identified (14.3\%), who had a total of 51 children under the age of five at the time of the focal years. Seven births were identified as occurring during non-survey years; as data for graduate student attendance is only available for years in which participants were interviewed, it is impossible to know if those births occurred during, before, or while on a break from graduate education. Women in graduate school were most likely to be mothers when they were surveyed in 1996 at ages 31-39, at which point nearly a third of graduate students, 29\%, were mothers. When respondents were age 25-33, 17.5\% were mothers. At the higher ages of $35-43,11.1 \%$ were mothers, and at ages $20-28$, only $4.8 \%$ were mothers. The unit of analysis for the remaining numbers presented below is the number of births, or children, and not the number of mothers. As the sample size for each year was very small, numerical frequencies are presented for most findings, while percentages are only calculated for the numbers that are totaled from all four years. It should be noted that the overall sample size is also quite small, and as a result, these findings might not be an accurate representation of the current state of graduate student fertility.

The first important thing to note is that nearly half (20, or $45.5 \%$ of all births) occurred in a year in which the mother was actively enrolled in graduate school. For $22.7 \%$ of births, mothers enrolled in graduate school for the first time after their child had been born, perhaps because these women used the opportunity of taking time off to have children to return to graduate education and bolster their earnings potential before returning to the labor market. The remaining $31.8 \%$ of births occurred while women had taken time off from graduate school, with women returning to graduate school after their child was born.

For the 20 births that occurred to women enrolled in graduate school at the time of birth, nearly half of women left or finished school the year after their child was born. This may be a result of two reasons; first graduate students may have timed their birth to coincide with the completion of their graduate program; second, graduate students may have left graduate school temporarily or permanently due to being unable to cope with the dual pressures of education and family. For at least one-third of these students, the latter seems to be the case. Of the nine women who left school the year after their child was born, three returned to graduate school at a later time, including two who returned when their child was under the age of five, and one who returned when their child was older.

Of the ten births that occurred before the mother started graduate school, many seemed to wait until their child was a bit older before beginning graduate school; only one started graduate school the year after their child was born, three started when their child was 2 years old, three when their child was 3 years old and two when their child was 4 years old. However, for the 12 of 14 women who had taken time off from graduate school for whom this information is available, women tended to return to graduate school when their children were younger; six returned a year after their child was born, five when their child was 2 years old, and only one when their child was older, at age four. Interestingly, 11 of these 12 women left their graduate programs more than a year before their child was born, indicating that for the vast majority of women who took time off of graduate school, they did not take time off specifically to have 
children, but then used the opportunity of having a child to quickly return to a graduate program they had left, or returned to graduate school in a different program.

Finally, in order to assess the childcare needs of graduate students, I collected information on the number of graduate students attending school with children at each age from 0 (year of birth) to 4. Most of the mothers in the sample who attended graduate school with children under the age of five did so when their children where age two or under. Twenty children (or $45 \%$ of total children) had mothers attending graduate school when they were born, 19 when they were one and 19 when they were two (43\% of total children in each year), 12 when they were three and 12 when they were four ( $27 \%$ of total children in each year). As noted above, these findings are based on a very small number of women, and so must be taken with caution. However, if these findings are able to be generalized to the women enrolled in graduate school, these findings would implicate that maternity leave - as well as childcare for very young children — would be a beneficial to graduate student mothers, as nearly half of women in this small sample have children while enrolled in school. Graduate mothers with children seem more likely to have children who are the younger ages of 0,1 or 2, while fewer are enrolled with children who are aged 3 or 4 . Further analysis with a larger sample size would bolster these findings, although data may be hard to obtain for this very select group of women.

\section{Policy Analysis}

While findings demonstrate that women enrolled in graduate school are increasingly having children when compared to women not enrolled in graduate school, disparities in motherhood rates still remain. Figure 3 demonstrates that women with graduate degrees have a later fertility pattern than women with lower levels of education, and while enrolled in graduate school their motherhood rates are significantly depressed. Why does this remaining disparity exist? Maternity leave policies and childcare options available to graduate students may explain part of this puzzle.

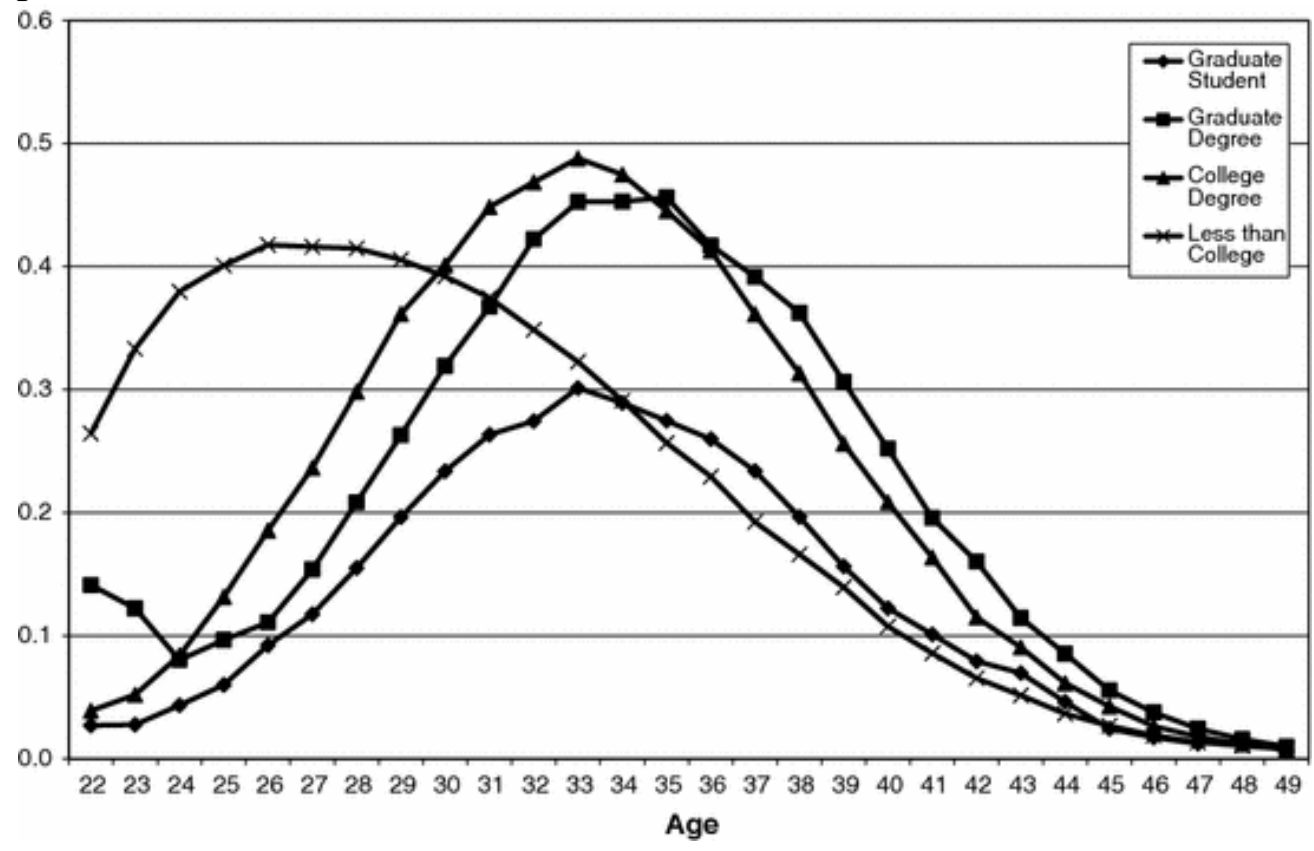




\section{Fig. 3}

Percent with children under five by age, degree: 2000

My findings (albeit based on a small sample size) suggest that nearly half of graduate mothers of young children give birth while enrolled in school. Clearly established maternity leave policies may affect an academic culture that discourages childbearing while in graduate school. Women with young children might still 'leak out' of the occupational pipeline during their graduate education due to cultural norms of the postgraduate educational system and stresses resulting from balancing childcare with graduate education. However, having an official policy in place gives recourse to women enrolled in postgraduate education who otherwise must negotiate the terms of childbearing and childcare without any policy to safeguard their decision to have a child.

Mason et al. (2007) conducted a brief survey of policies available to graduate students and found that of 62 schools examined, $26 \%$ of programs had a maternity or parental leave policy, $10 \%$ had paid maternity leave, $76 \%$ had on-site childcare programs, $50 \%$ had subsidies for childcare, and $10 \%$ had programs for emergency backup childcare. However, they do not present information on the specifics of these maternity leave policies. In order to update the information collected by Mason et al. (2007), I used web searches to collect information on the maternity leave and childcare options available to students at the top 20 doctoral programs, as defined by the 2008 U.S. News and World Report rankings (http://colleges.usnews.rankingsandreviews.com/usnews/ edu/college/rankings/brief/t1natudoc_brief.php retrieved June 30, 2008). Findings are presented in Table 7. These findings cannot be said to be representative of all graduate programs, but rather represent the policies at leading schools, which may serve as models to lower ranking schools. Additionally, policies were specifically collected in Schools of Arts and Sciences (or the equivalent) and different policies may be in place for students obtaining a professional degree (see Boulis and Jacobs 2007 for a discussion of maternity leave policies for medical students). Given that the focus of this paper is female graduate students, this policy analysis focuses specifically on policies available to women enrolled in graduate schools. In most cases, childcare policies are available to both male and female graduate students, although in some cases leave after the birth of a child was only available to female graduate students. Specific information on which policies were gender-specific was not collected.

\section{Table 7}

Maternity leave policies in top 20 research universities (defined by usnews.com 2008 report)

\begin{tabular}{|c|c|c|c|}
\hline & $\begin{array}{l}\text { Number of schools } \\
\text { with policy } \\
(N=20)\end{array}$ & $\begin{array}{l}\text { Percent of total } \\
\text { schools }(N=20)\end{array}$ & $\begin{array}{l}\text { Percent of schools with } \\
\text { known maternity policy } \\
(N=12)\end{array}$ \\
\hline \multicolumn{4}{|c|}{ Maternity/parental leave policies available to graduate students } \\
\hline $\begin{array}{l}\text { Official school-wide } \\
\text { maternity or parental } \\
\text { leave }\end{array}$ & 13 & $65 \%$ & \\
\hline
\end{tabular}




\begin{tabular}{|c|c|c|c|}
\hline & $\begin{array}{l}\text { Number of schools } \\
\text { with policy } \\
(N=20)\end{array}$ & $\begin{array}{l}\text { Percent of total } \\
\text { schools }(N=20)\end{array}$ & $\begin{array}{l}\text { Percent of schools with } \\
\text { known maternity policy } \\
(N=12)\end{array}$ \\
\hline \multicolumn{4}{|l|}{ Length of leave available } \\
\hline 6 weeks & 4 & & $33.33 \%$ \\
\hline 8 weeks & 4 & & $33.33 \%$ \\
\hline 12 weeks & 2 & & $16.66 \%$ \\
\hline 1 quarter & 1 & & $8.30 \%$ \\
\hline 2 quarters & 1 & & $8.30 \%$ \\
\hline No information & 1 & & \\
\hline $\begin{array}{l}\text { Students are paid during } \\
\text { leave }\end{array}$ & 11 & $55 \%$ & $91.66 \%$ \\
\hline $\begin{array}{l}\text { Time to degree is } \\
\text { extended }\end{array}$ & 9 & $45 \%$ & $75 \%$ \\
\hline Funding is extended & 4 & $20 \%$ & $33.33 \%$ \\
\hline \multicolumn{4}{|c|}{ Year maternity/parental leave policy enacted $(N=13)$} \\
\hline 2004 & 2 & & $15.38 \%$ \\
\hline 2006 & 4 & & $30.77 \%$ \\
\hline 2007 & 1 & & $7.69 \%$ \\
\hline 2008 & 1 & & $7.69 \%$ \\
\hline No information & 5 & & $38.46 \%$ \\
\hline \multicolumn{4}{|c|}{ Childcare options available to graduate students } \\
\hline $\begin{array}{l}\text { On-site childcare } \\
\text { center }\end{array}$ & 12 & $60 \%$ & \\
\hline
\end{tabular}




\begin{tabular}{|c|l|l|l|}
\hline & $\begin{array}{l}\text { Number of schools } \\
\text { with policy } \\
(\boldsymbol{N}=\mathbf{2 0})\end{array}$ & $\begin{array}{l}\text { Percent of total } \\
\text { schools }(\boldsymbol{N}=\mathbf{2 0})\end{array}$ & $\begin{array}{l}\text { Percent of schools with } \\
\text { known maternity policy } \\
\mathbf{( N = 1 2 )}\end{array}$ \\
\hline Childcare subsidies & 6 & $30 \%$ & \\
\hline $\begin{array}{c}\text { Backup emergency } \\
\text { care available }\end{array}$ & 5 & $25 \%$ & \\
\hline
\end{tabular}

In these leading institutions, maternity or parental leave policies exist at a much higher rate than is found by Mason et al. (2007); 65\% of these programs, or 13 out of 20 have some kind of maternity or parental leave policy. Specific information was collected for 12 programs; the remaining program had information on its website indicating that a policy was in place and gave the date of implementation, but did not present details of the policy. Of the 12 policies for which information is available, one-third give students 6 weeks leave and an additional one-third give students 8 weeks of leave. Only one-third (4) of programs have a maternity leave policy that lasts 12 weeks or longer, which is the length of the Family Medical Leave Act.

Almost all of these leading schools which had maternity leave continued to pay students during the leave; 11 of 12, representing 55\% of the total schools. Nine schools (45\% of total schools) extended the time limits on receiving a degree to students who took maternity or parental leave. This is an important policy detail, as students who take maternity leave but are not able to extend time to degree are disadvantaged in relation to students who do not take leave, as they have less overall time to complete their graduate work. Additionally, only four schools (20\% of total schools) extend graduate funding for students who take leave, meaning the 'paid' maternity leave is in most cases a continuation of regular funding for graduate students with no additional funding available for the time needed to make up for the work not conducted while on leave.

The majority of these maternity leave policies were enacted in recent years; 8 of 13 were established in 2004 or later, and five programs did not have information on when the policy was created. This indicates that before 2004, at most only 25\% of the leading graduate programs had a maternity leave policy in place. These findings are consistent with Mason et al. (2007), who find that in 2006 only $26 \%$ of 60 programs examined had a maternity leave policy in place. The fact that the majority of maternity leave policies are very recently established means that the overall increase in fertility rates of graduate students found in this paper are probably not a result of a widespread increase in family-friendly policies for graduate students.

Finally, a brief review of childcare available in these same 20 schools finds that 12 schools (60\%) have on-sight childcare that students can use. Also, only six (30\%) have childcare subsidies available to graduate students. Five (25\%) have emergency backup childcare for graduate students. The above findings on fertility timing suggest that many graduate student mothers attend school while their children are very young-ages 0-2. Children at these ages are very dependent on their caretaker. Increasing both on-sight childcare options and childcare subsidies for graduate students would aid in the education-life balance of these women. 


\section{Discussion}

In terms of fertility change over the past 40 years, all three hypotheses are supported by the data, with a few caveats. The first hypothesis states that graduate student motherhood rates should increase over time as a result of an institutional effect. The data shows that age-standardized motherhood rates of graduate student fertility declined between 1970 and 1980 before increasing afterwards. The second hypothesis states that graduate student motherhood rates should increase relative to all other women's motherhood rates. This comparison controls for national level changes in birth control and abortion availability, and other unmeasured national level changes that could affect overall fertility rates in the time period studied. Ratios support this hypothesis, although regressions show a decrease in motherhood among graduate students as compared to all other women between 1990 and 2000.

The third hypothesis states that graduate students would become more like other college graduates who are not enrolled in school over time, in terms of their motherhood rates. These ratios and regressions control for the effect of different attitudes towards combining work and family among college graduates, as well as national trends in fertility. Ratios and regressions show support for this hypothesis for the time period of 1970-1990, although both ratios and regressions show a decline in the relative motherhood rates of graduate students between 1990 and 2000, similar to the findings in the ratios of graduate students to all women. This suggests that between 1990 and 2000 the institutional effect might have reached its limit in the ability to change women's behavior, or that some other unknown effect is at work in this decade. These results also suggest that as women are increasingly enrolled in graduate education, their status as enrolled graduate students is less salient to their childbearing patterns, and they become more similar to other women.

One important caveat to note is that the movement in motherhood rates is primarily among nongraduate students over time, and graduate students show remarkably little movement in their motherhood rates in the time period studied. This means that changes in motherhood ratios are not a result of actual increases in fertility, but rather the result of little movement in motherhood rates among graduate students, and greater decline in fertility among non-graduate students, including both college graduates and all women. Graduate students are not increasing their motherhood rates to a great extent; rather, they defy trends exhibited by other groups of women by not demonstrating a decrease in motherhood rates.

\section{Timing of Fertility Change}

One question that arises from these results is the timing of change. The greatest decade of change in women's enrollment is the 1970s, but the greatest decade of change in motherhood rates is the 1980s, and graduate student's absolute rates of motherhood (once age standardized) actually decrease between 1970 and 1980. The answer to this question can be found in Kanter (1977, p. 219) who writes that women who find themselves a scarce presence in an institution might "try to turn the notoriety of publicity to advantage, or to find ways to become socially invisible." Women enrolled in graduate education in 1970 were scarce, and may very well have been 'socially invisible,' and therefore "demonstrate their gratitude for being included by not criticizing their situation or pressing for any more advantage” (Kanter 1977, p. 229). As more women entered graduate school between 1970 and 1980, however, they became more visible in 
the organization. Over time, the increasing numbers of women enrolled in graduate education have more power to affect institutional change, as alluded to in the original hypothesis. Thus, a "pioneer effect" occurs; as women initially increase to a significant presence in an institution, they are more cautious about deviating from the (male-centered) norms of that institution. However, when they are established in that institution and no longer "pioneering," they use their increasing power within the institution to change the culture to their advantage; in this case, increasingly having young children while a member of the institution. This "pioneer effect" explains both the decline in absolute age-adjusted fertility rates between 1970 and 1980, and also why the greatest period of change is the decade of the 1980s, and not the 1970s.

\section{Age Differences in Fertility Change}

Another question that arises from these results is the age of those changing their motherhood patterns. Between 1970 and 1980, motherhood rates decline for women under the age of 30 . After that, rates among these women stay stable, for the most part, throughout the time period studied. The vast majority of changes occur among women over the age of 30; these women continually increase their recent motherhood rates in the time period studied. Why are older women the only ones with changing probabilities of motherhood while in graduate school after 1980 ? If we assume Kanter's theory of relative numbers is correct, then perhaps these women are more sensitive to changes in institutional culture; women over 30 are closer to the end of their fecund years, and therefore are more constrained in the decision to delay childbirth. Therefore, they are more likely to react to institutional shifts in culture by increasing childbirth, which would explain the increasing probability of these women to have children under the age of five.

Alternatively, the changing patterns of motherhood among older women enrolled in graduate education might be a result of a motherhood delay among high achieving women. Such a delay would explain the increased probability of having a child under the age of five at later ages. The direction of causality for motherhood and enrollment in graduate education is impossible to determine; older women may decide to have children while they are taking time out of the workforce to enroll in graduate education - when they have a more flexible schedule. Alternatively, it may be that women who are older decide to go back to school after having children, possibly after taking some time out of the workforce, to increase their human capital when they return to the workforce. Data on timing of fertility shows that a little over half of female graduate students with children are women who have either returned to graduate school after having a child while out of the education system, or started school after having a child. Future research would be able to address these issues of causality and process by engaging this topic qualitatively.

Finally, it may be that different age structures and different levels of support for new mothers in specific fields of study or graduate degree programs can explain the increasing rate of motherhood among older women. For instance, if most women who attend graduate school at older ages are enrolled in programs that are increasingly family-friendly, while younger women attend programs that remain stable in their family-friendlyness, this would explain why change has occurred for older but not younger women. Unfortunately, specific fertility data by field of study is not available at this time; future data collection efforts can address this issue.

\section{Policy Implications}


The issue of motherhood among highly educated women is salient throughout their careers. It is especially important in light of the divergent occupational outcomes of men and women. The process leading to the upper ranks of the occupational hierarchies within jobs requiring graduate education has been described as a 'pipeline,' with large numbers of people entering the pipe with many 'leaks,' as people drop out at different stages (Allen and Castlement 2001; Valian 2004). One reason for this leaky pipeline may be the dearth of support for new mothers; as Mason and Goulden (2002) note, women with PhDs who have at least one child early in their careers (defined as earlier than 5 years after obtaining their $\mathrm{PhD}$ ) are $24 \%$ less likely in the sciences and $20 \%$ less likely in the humanities and social sciences to ever achieve tenure, when compared to men with PhDs and early-career children. With an increase in policies addressing problems associated with balancing childbirth and childcare with graduate education, it is possible that a more equitable gender balance in elite professions can eventually be achieved. ${ }^{2}$

Having a more equitable gender balance in elite professions is advantageous; by increasing the candidate pool, institutions can hire and retain the best candidates in their fields. Graduate education is one of the earlier stages at which women leak out of the occupational pipeline. One of the most important findings of this study is that women (especially older women) enrolled in graduate school are increasingly likely to be the mothers of young children, relative to previous cohorts, and that they are more similar to non-students, and are especially similar to other college graduates. Additionally, as the number of women enrolled in graduate school has increased relative to men, the absolute number of graduate students who have to deal with childcare issues has also increased. Finally, an examination of the timing of childbirth, albeit based on a small sample, suggests that nearly half of graduate student mothers of children under five have their children while enrolled in graduate school, and many attend school while their children are very young, at age two or younger.

As this study demonstrates, women enrolled in graduate school are becoming increasingly similar in their motherhood rates to non-graduate students, and especially similar to other college graduates who are not enrolled in graduate school. These other college graduates who are not enrolled in school are likely covered by such government policies as the Family Medical Leave Act, which grants 12 weeks unpaid leave to those with new children, and which has thus far not been interpreted to include graduate students. Women outside of graduate school may also have access to work-related maternity leave policies that go beyond the Family Medical Leave Act. As shown by the policy analysis, two-thirds of maternity leave policies available to graduate students are for less than 12 weeks, and $35 \%$ of top graduate programs have no maternity leave policies at all. Mason et al. (2007) find in a broader study that as many as $74 \%$ of graduate programs do not have an official maternity leave policy.

In order to remain competitive with the non-academic world, graduate programs that have an interest in retaining female students who wish to have children during graduate school must address their specific needs. Establishing and improving the maternity leave and childcare policies available to these women might decrease the amount of women leaking out of the occupational pipeline during this stage. Additionally, reducing penalties for women who have children during graduate school (such as limits on time to degree) could help these women succeed in completing their graduate education. Future research can determine the extent to 
which implementing such policies can ultimately improve the ratio of women to men in elite occupations, and prevent women from 'leaking out' early in the pipeline of these careers.

\section{References}

Allen, M., \& Castlement, T. (2001). Fighting the pipeline fallacy. In A. Brooks \& A. Mackinnon (Eds.), Gender and the restructured university. Philadelphia: The Society for Research and Open University Press.

Boulis, A. K., \& Jacobs, J. A. (2007). Women becoming doctors: Women's entry in the medical profession in the United States, 1970-2000. Ithaca, NY: Cornell University Press.

Conrad, L., \& Phillips, E. M. (1995). From isolation to collaboration: A positive change for postgraduate women? Higher Education, 30, 313-322. doi:10.1007/BF01383755.

Cooksey, E. C., \& Rindfuss, R. R. (2001). Patterns of work and schooling in young adulthood. Sociological Forum, 16(4), 731-755. doi:10.1023/A:1012842230505.

Dugger, K. (2001). Women in higher education in the United States: 1. Has there been progress? The International Journal of Sociology and Social Policy, 21(1), 118-130. doi:10. 1108/01443330110789637.

Fleer, E. (2004, September, 14). Ditch the boyfriend. The Chronicle of Higher Education.

Garms, I. (2006, April 27). A pregnant pause. The Chronicle of Higher Education.

Gauthier, A. H., \& Hatzius, J. (1997). Family benefits and fertility: An econometric analysis. Population Studies, 51(3), 295-306. doi:10.1080/0032472031000150066.

Goldin, C. (2004). The long road to the fast track: Career and family. The Annals of the American Academy of Political and Social Science, 596, 20-35. doi:10.1177/ 0002716204267959.

Goldin, C., \& Katz, L. F. (2002). The power of the pill: Oral contraceptives and women's career and marriage decisions. The Journal of Political Economy, 110(4), 730-770. doi:10.1086/ 340778.

Jacobs, J. A. (1996). Gender inequality and higher education. Annual Review of Sociology, 22, 153-185. doi:10.1146/annurev.soc.22.1.153.

Jacobs, J. A., \& Winslow, S. E. (2004). The academic life course, time pressures, and gender inequality. Community Work \& Family, 7(2), 143-161. doi:10.1080/1366880042000245443.

Houseknecht, S. K., \& Spanier, G. B. (1980). Marital disruption and higher education among women in the United States. The Sociological Quarterly,21, 375-389. doi:10.1111/j.1533-8525. 1980.tb00619.x. 
Kanter, R. Moss. (1977). Men and woman of the corporation. New York: Basic Books, Inc., Publishers.

Kemkes-Grottenthaler, A. (2003). Postponing or rejecting parenthood? Results of a survey among female academic professional. Journal of Biosocial Science, 35, 213-226. doi:10.1017/ S002193200300213X.

Killien, M. (1987). Childbearing choices of professional women. Health Care for Women International, 8(2-3), 121-131.

Mason, M. A., \& Goulden, M. (2002). Do babies matter? Academe, 88(6), 21-27.

Mason, M. A., \& Goulden, M. (2004a). Marriage and baby blues: Redefining gender equity in the academy. The Annals of the American Academy of Political and Social Science, 596, 86-103. doi:10.1177/0002716204268744.

Mason, M. A., \& Goulden, M. (2004b). Do babies matter (Part II)? Closing the baby gap. Academe, 90(6), 10-15.

Mason, M. A., Goulden, M., \& Frasch, K. (2007). Graduate student parents: The underserved minority. Communicator. Council of Graduate Schools,40(4), 1-5.

Miree, C. E., \& Frieze, I. H. (1999). Children and careers: A longitudinal study of the impact of young children on critical career outcomes of MBAs.Sex Roles, 41(11/12), 787-808. doi:10. 1023/A:1018876211875.

Morgan, S. P. (1996). Characteristic features of modern American fertility. Population and Development Review, 22 (Supplement: Fertility in the United States: New Patterns, New Theories), 19-63.

Preston, S. H., Heuveline, P., \& Guillot, M. (2001). Demography: Measuring and modeling population processes. Oxford: Blackwell Publishing.

Rindfuss, R. R., Bumpass, L., \& St. John, C., (1980). Education and fertility: Implications for the roles women occupy. American Sociological Review, 45(3), 431-447. doi:10.2307/2095176.

Rindfuss, R. R., Morgan, S. P., \& Offutt, K. (1996). Education and the changing age pattern of American fertility: 1963-1989. Demography, 33(3), 277-290. doi:10.2307/2061761.

Rothblum, E. D. (1988). Leaving the ivory tower: Factors contributing to women's voluntary resignation from academia. Frontiers, 10(2), 14-17. doi:10.2307/3346465.

Ruggles, S., Sobek, M., Alexander, T., Firthc, C. A., Geoken, R., Hall, P. K., et al. (2005). Integrated public use microdata series: Version 3.0 (machine-readable database). Minneapolis, MN: Minnesota Population Center. 
Sandefur, G. D., Eggerlilng-Boeck, J., \& Park, H. (2005). Chapter 9: Off to a good start? Postsecondary education and early adult life. In R. A. Settersten Jr., F. F. Furstenburg Jr., \& R. C. Rumbaut (Eds.), On the frontier of adulthood (pp. 292-392). Chicago: The University of Chicago Press.

Schweber, S. (2005, April 12). It’s all an illusion. The Chronicle of Higher Education.

Smulyan, L. (2004). Redefining self and success: Becoming teachers and doctors. Gender and Education, 16(2), 225-245. doi:10.1080/09540250310001690591.

Spalter-Roth, R., \& Kennelly, I. (2004). The best time to have a baby: Institutional resources and family strategies among early career sociologists.ASA Research Brief (pp. 1-18).

Thornton, A., Axinn, W. G., \& Teachman, J. D. (1995). The influence of school enrollment and accumulation on cohabitation and marriage in early adulthood. American Sociological Review, 60(5), 767-774. doi:10.2307/2096321.

U.S. Department of Education, National Center for Education Statistics. (2003). Digest of Education Statistics. Tables 267, 270 \& 273.

Valian, V. (2004). Beyond gender schemas: Improving the advancement of women in academia. NWSA Journal, 16(1), 207-220. doi:10.2979/NWS.2004.16.1.207.

van Anders, S. M. (2004). Why the academic pipeline leaks: Fewer men than women perceive barriers to becoming professors. Sex Roles, 50(9/10), 511-521. doi:10.1007/s11199-004-5461-9.

Weeks, J. R. (2002). Population: An introduction to concept and issues (8th ed.). Wadsworth Group.

Williams, J. C. (2004a, April 20). Singing the grad-student baby blues. The Chronicle of Higher Education.

Williams, J. C. (2004b, June 17). Easing the grad-student baby blues. The Chronicle of Higher Education.

\section{Footnotes}

1) This measurement does not take into account field of study or type of degree. As shown in Table 1, the enrollment rates of women vary considerably across type of degree. Enrollment rates of women probably also vary considerably across specific fields of study. Unfortunately, information on field of study is not available in any longitudinal study that includes information on graduate student enrollment and fertility rates, and so cannot be taken into account in this study. This measurement also includes both full time and part time enrolled students, as information on whether students were enrolled full time or part time was not collected in the U.S. census. Both female enrollment rates and motherhood rates can vary considerably by field of study and whether enrollment was part time or full time. Part time students may not be enrolled in a degree seeking program, and may be balancing the decision to have a child with both school 
enrollment and formal employment. The age structure of female graduate students may also vary considerably by field of study, as in some fields of study it is standard practice to work for several years before enrolling in graduate school, and in some fields most students enter graduate school immediately following college. While this should not affect age-standardized examinations of motherhood, this will affect the extent to which findings are relevant to different degree programs, especially if motherhood is concentrated among older students. This paper cannot address these questions due to the discussed data constrains. Future data collection efforts can address the degree to which findings can vary by field of study.

2) With these data it is impossible to determine the exact extent to which policies affect the fertility of graduate students. Furthermore, between graduate programs, fields of study, and universities, there is considerable variation in motherhood rates, the representation of women, the age structure of graduate students, and family friendly policies. Future research would be able to examine the connection between policy and fertility in greater depth, by examining specific programs and fields of study within schools, the gender and age structure of their programs, their fertility policies and childcare options, and the fertility rates of their female graduate students. 